\title{
INOVASI KESENIAN RAKYAT KUDA LUMPING DI DESA GANDU, KECAMATAN TEMBARAK, KABUPATEN TEMANGGUNG
}

Nur Rokhim

Institut Seni Indonesia (ISI) Surakarta

Jalan Ki Hadjar Dewantara No. 19 Kentingan, Jebres, Surakarta 57126

\begin{abstract}
Abstrak
Demam kesenian rakyat kolaborasi Leakan di Temanggung rupanya sudah tidak dapat dibendung lagi. Para seniman senior rata-rata menolak kehadiran kolaborasi tersebut, mereka merasa risih dengan pengembangan seni pertunjukan yang demikian. Akhirnya Dinas melarang pertunjukan kolaborasi Kuda Lumping dengan tari Leak, Pendet dan Barong Bali. Hal ini dimaksudkan untuk mengembalikan eksistensi pertunjukan Kuda Lumping seperti semula sebagai seni yang mempunyai ciri khas Temanggung. Kesenian Kuda Lumping Sri Budoyo berada pada situasi yang rumit, di tengah-tengah tuntutan selera masyarakat yang semakin beraneka ragam. Tekad masyarakat pendukung kesenian sudah bulat untuk menjaga dan melestarikan kesenian Kuda Lumping supaya tetap eksis dengan ciri khasnya. Berbagai permasalahan mitra sebagi akibat masuknya kesenian luar daerah yang mengusik eksistensi kesenian lokal sebagai ciri khas daerah, maka akan ditawarkan solusi untuk mengatasi permasalahan yang dihadapi. Inovasi adalah sebuah cara yang akan dilakukan sebagai solusinya. Inovasi yang dilakukan adalah pemberdayaan anak-anak sebagai generasi penerus kesenian Kuda Lumping di desa Gandu II, yang nantikan akan memegang kendali kesenian di desa tersebut. Anak-anak diberi pelatihan tari Geculan sebagai dasar kepenarian mereka, gerak-gerak yang disusun disesuaikan dengan usianya.
\end{abstract}

Kata kunci: Inovasi, Kesenian rakyat, Kuda Lumping.

\section{Abstract}

The folk art fever of the Leakan collaboration in Temanggung apparently cannot be stopped anymore. The average senior artists reject the presence of the collaboration, they feel uncomfortable with the development of such performing arts. Finally the Office banned the performance of the Kuda Lumping collaboration with the Leak, Pendet and Barong Bali dances. This is intended to restore the existence of the Kuda Lumping performance as originally as an art that has a characteristic Temanggung. Sri Budoyo's Kuda Lumping Art is in a complicated situation, amidst the increasingly diverse demands of the people's tastes. The determination of the people supporting the arts has been unanimous to maintain and preserve the Kuda Lumping art in order to continue to exist with its trademark. Various partner problems as a result of the entry of arts outside the region that disturb the existence of local arts as a regional characteristic, will be offered a solution to overcome the problems faced. Innovation is a method that will be carried out as a solution. The innovation carried out was the empowerment of children as the next generation of Kuda Lumping art in the village of Gandu II, who were looking forward to taking control of the arts in the village. The children were given Geculan dance training as a basis for their dance, the movements arranged according to their age.

Keywords: Innovation, Folk art, Kuda Lumping. 


\section{PENDAHULUAN}

Desa Gandu merupakan salah satu desa yang berada di kecamatan Tembarak, kabupaten Temanggung. Desa ini memiliki luas wilayah $125 \mathrm{~h}$ dengan jumlah penduduk 1620 jiwa. Perekonomian yang menjadi sumber penghasilan utama masyarakatnya adalah pertanian yaitu pertanian tembakau, jagung, cabai, dan kopi. Pertanian masyarakatnya sangat bergantung kepada iklim dan cuaca. Potensi kesenian yang terdapat di desa Gandu lebih kurang 7 kesenian yang hidup dan berkembang di dusun tersebut, antara lain, Kethoprak, Kuda Kepang "Sri Budaya”, Topeng Ireng "Wahyu Rimba Manunggal", Jathilan, Lengger Wonosobo, Sandul, dan Campursari. Beberapa dari kesenian tersebut telah berhasil menjuarai beberapa festival yang diselenggarakan pemerintah kabupaten Temanggung. Selain itu sempat mendapat kesempatan menjadi salah satu pengisi acara dalam HUT TMII Jakarta. Kesenian yang berkembang pesat adalah kesenian Kuda Kepang dan kesenian Topeng Ireng. Ada beberapa kesenian yang sudah mulai ditinggal peminatnya. Hal ini dipengaruhi oleh beberapa faktor seperti kurangnya pendukung sajian seperti kesenian Kethoprak dan Sandul.

Kebanyakan dari mereka hanya mengandalkan hasil dari pertanian tembakau sehingga jika terjadi gagal panen mereka akan bekerja keluar daerah untuk memenuhi kebutuhan. Faktor tersebut yang membuat kesenian ini mulai berkurang anggotanya. Selain itu kesibukan ketika sudah memasuki musim tembakau membuat mereka tidak bisa beranjak untuk meninggalkan aktivitas panen tembakau. Kesenian Kuda Lumping Sri Budaya dari desa Gandu sudah cukup dikenal di kabupaten Temanggung maupun luar Temanggung. Menurut kepala dinas Kebudayaan, kelompok ini merupakan salah satu kesenian kuda kepang yang masih memegang pakem sebagai kesenian asli Temanggung. Seiring perkembangan jaman masyarakat mulai tertarik dengan kesenian luar yang belum pernah mereka lakukan. Beberapa kelompokkesenian di Temanggung melakukan kolaborasi kesenian asli Temanggung dengan kesenian dari Bali. Unsur kesenian Bali ini meliputi tari, busana, dan juga musik. Mereka sering mengkolaborasikan kesenian kuda kepang Temanggung dengan kesenian Leak, Barong, tari Pendet, dan tari Cendrawasih. Permasalahan yang terjadi adalah mereka mampu mengkolaborasikan kesenian tersebut namun tidak mampu mempertanggunjawabkan karya mereka. Mereka mengambil unsur Bali guna memenuhi kebutuhan estetis saja. Melihat kondisi ini kelompok kesenian kuda lumping Sri Budaya mengambil sikap untuk tetap bertahan dengan pakem yang telah ada. Namun permintaan masyarakat rupanya harus dipertimbangkan, mereka menghendaki pertunjukan kesenian kuda lumping seperti yang dilakukan oleh kelompok lainya. Kolaborasi adalah sebuah cara untuk mengurangi kebosanan penonton yang semakin meningkat seleranya.

\section{SEPUTAR KOLABORASI}

Kesenian Kuda Lumping harus tetap dilestarikan dengan menjaga keaslianya supaya tidak kehilangan ruh sebagai kesenian asli Temanggung. Kepala desa Gandu merasa prihatin kepada kesenian Kuda Lumping yang terjadi di Temanggung saat ini. Mereka melakukan kolaborasi yang 
kurang tepat, memasukkan tari Bali seperti Leak dan Pendet sebagai bagian dari pertunjukan Kuda Lumping. Ketakutan ini menyelimuti anggota kelompok Sri Budaya, kesenian yang dirintis dan diperjuangkan selama ini akan dirusak oleh kehadiran kesenian dari luar daerah. Kuda lumping Sri Budaya merupakan kelompok kesenian yang usianya tergolong lama atau senior. Banyak group kuda lumping di lereng Gunung Sumbing yang dilatih hinga menjadi kesenian yang mapan.

Kepala Dinas Kebudayaan dan Pariwisata mengemukakan ada ratusan kelompok kesenian kuda lumping di Temanggungan, namun hanya tersisa dua kelompok saja yang masih mempertahankan pakem lama. Yakni Turongggo Mudo asal Tlogomulyo dan Sri Budaya asal Gandu, Tembarak. Jaran Kepang Temanggungan memiliki identitas yang menjadi ciri khas. Yakni musik dari perangkat gamelan murni serta pemainnya yang menggunakan baju putih, rompi, dan ikat kepala. Dia berharap group-group kesenian kuda lumping bisa mempertahankan keaslian dengan tidak latah mencampur dengan kesenian lain.

Menurutnya generasi tua prihatin dengan kolaborasi kesenian kuda lumping di Temanggung saat ini yang memasukkan tari pendet dan Leak pada pementasan. Kolaborasi itu merusak pakem kuda lumping yang sudah dibakukan. Kuda lumping itu ada pakemnya, tidak boleh sembarangan dikolaborasi dengan kesenian lain. Nah melalui pementasan sebagai pembelajaran pada generasi muda.

Geliat seni tradisional Kuda Lumping di kabupaten Temanggung semakin semarak, hal ini ditandai dengan usaha kaum remaja yang ingin mempopulerkan kesenian tersebut. Pengaruh teknologi dunia maya semakin mendorong keinginan generasi muda untuk membangkitkan kesenian dengan cara melakukan kolaborasi dengan kesenian lain supaya kesenian yang dimiliki menjadi semakin menarik dan diminati masyarakat. Namun usaha yang dilakukan tidak mempertimbangkan segi keindahan tarinya, yang penting pakaiannya gelamor dan meriah. Apabila dilihat dari bentuk gerakan tarinya, jelas tari Kuda Lumping dan tari Pendet akan sulit dikolaborasikan karena asal tari yang berbeda dan latarbelakang budaya kemunculan tari yang berbeda juga. Bahan baku penari yang biasanya menari Gambyongan, kemudian menari Pendet tanpa pelatihan akan terasa kaku dan jauh dari gerak tari gaya Bali. Apabila ini dipaksakan maka akan muncul gerakan tari improfisasi gaya Bali namun rasa Jawa. Tidak dapat dipungkiri memang sekarang pelaku kesenian agak sedikit berkurang, terutama penari wanita. Seteleh menikah biasanya seorang wanita sudah tidak sanggup menari lagi.

Demam Leakan di Temanggung rupanya sudah tidak dapat dibendung lagi, terutama kawula muda yang senang kepada hal yang baru dan animo sebagian masyarakat yang menerima kehadiran kolaborasi. Para seniman senior dan para orang tua rata-rata menolak dengan kehadiran kolaborasi tersebut, mereka merasa risih dengan pengembangan seni pertunjukan yang demikian. Penolakan ini akhirnya didukung oleh dinas terkait, seperti Dinas Kebudayaan, Pariwisata, Pemuda dan Olah Raga. Akhirnya Dinas melarang petunjukan kolaborasi Kuda Lumping dengan tari Leak, Pendet dan Barong Bali. Hal ini dimaksudkan untuk mengembalikan 
eksistensi pertunjukan Kuda Lumping seperti semula sebagai seni yang mempunyai ciri khas Temanggung.

Dikutib dari http://kabare.id. Para pengiat seni sepakat untuk melestarikan dan menjaga pakem tari Kuda Lumping Temanggungan sebagai kesenian khas kabupaten Temanggung. Seniman sekaligus budayawan Indonesia, Didik Hadiprayitno atau yang terkenal dengan nama Didik Ninik Thowok mengamati, pertunjukan seni Kuda Lumping di Kabupaten Temanggung belakangan ini telah dikolaborasikan dengan kebudayaan asal Pulau Bali, seperti Leak dan Tari Pendhet. Kendati tidak menyalahi aturan, namun fenomena tersebut dianggap kurang pas. Pasalnya, para pegiat seni yang ada belum memahami benar bagaimana sebenarnya kesenian asal Pulau Bali yang kental akan muatan sejarah lokal setempat. "Saya kenal dengan banyak sesepuh seni serta budayawan asal Bali, pun demikian halnya dengan kebudayaan mereka. Jadi, sah sah saja mengkolaborasikan seni jathilan dengan Leak maupun Tari Pendhet. Tapi harus mendalami dan tahu dulu benang merahnya seperti apa biar kita gak diisin isini orang Bali.

Sebagai kepala desa di Gandu sudah sewajarnya mendukung kebijakan kepala Dinas yang bergerak dibidang kesenian. Kotim selaku kepala desa Gandu mempunyai komitmen bersama masyarakart untuk menjaga dan melestarikan Kuda Lumping kelompok Sri Budaya supaya terjaga kesalianya sebagai kesenian khas Temanggung. Seni pertunjukan tidak terlepas dengan masyarakat pendukungnya, untuk memenuhi selera masyarakat maka tetap diadakan kolaborasi dan inovasi. Sekarang tidak mengadopsi kesenian dari luar daerah, namun mengembangkan kesenian daerah yang bentuk tarinya tidak terlalu jauh berbeda dengan tari induk.

\section{PROSES INOVASI}

Kesenian Kuda Lumping Sri Budaya berada pada situasi yang rumit, di tengahtengah tuntutan selera masyarakat yang semakin beraneka ragam. Tekad masyarakat pendukung kesenian sudah bulat untuk menjaga dan melestarikan kesenian Kuda Lumping supaya tetap eksis dengan ciri khasnya. Berdasarkan permasalahan mitra pada Bab sebelumnya maka akan ditawarkan solusi untuk mengatasi permasalahan yang dihadapi. Inovasi adalah sebuah cara yang akan dilakukan sebagai solusinya. Menurut Everett M. Rogers, pengertian inovasi adalah suatu ide, gagasan, objek, dan praktik yang dilandasi dan diterima sebagai suatu hal yang baru oleh seseorang atau pun kelompok tertentu untuk diaplikasikan atau pun diadopsi.

Sebagai produk kebudayaan, kesenian tradisional tak dapat dipisahkan dari masyarakat, karena seni tradisi tumbuh dan berkembang bersama masyarakat secara turun temurun. Eksistensi kesenian tradisi menjadi identitas yang memiliki ciri khas tersendiri dari masyarakat tersebut. Sehingga dalam bahasan kesenian tradisi, masyarakat memiliki peran penting dalam perkembangan kesenian-kesenian yang telah menjadi hak milik mereka. Hilang dan hancurnya kesenian tradisi tersebut tergantung pada masyarakat itu sendiri.

Inovasi yang dilakukan adalah pemberdayaan anak-anak sebagai generasi penerus kesenian Kuda Lumping di desa Gandu, yang nantikan akan memegang kendali kesenian di desa tersebut. Anak-anak diberi pelatihan tari Geculan sebagai dasar 
kepenarian mereka, gerak-gerak yang disusun disesuaikan dengan usianya. Materi yang dipilih adalah tari Geculan, nantinya akan digunakan sebagai bahan kolaborasi dengan tari Kuda Lumping. Tarian baru yang diciptakan diharapkan dapat menjadi salah satu ikon di desa Gandu.

Penggarapan bentuk pertunjukan kesenian rakyat desa Gandu meliputi gerak tari, rias busana dan karawitan tarinya. Gerak tari Kuda Lumping sendiri tidak luput dari penyempurnaan dan penambahan gerak atraktif supaya semakin energik dan tidak membosankan. Penyusunan gerak tari Geculan dimulai dari awal, mulai penyusunan konsep dan ide garap sampai kepada pemilihan rias busana dan musiknya.

Pelestarian seni tradisioanal dengan cara melakukan inovasi merupakan upaya untuk menyesuaikan bentuk pertunjukan dengan tuntutan jaman. Hal ini dilakukan karena seni tradisional harus mampu beradaptasi dengan perkembangan jaman.

Inovasi kesenian Kuda Lumping melalui kegiatan pelatihan tari untuk anakanak di desa Gandu merupakan upaya untuk melestarikan kesenian tradisional. Generasi penerus kesenian harus dipersiapkan untuk nanti dan sekarang. Hasil pelatihan tari nantinya akan digunakan sebagai pengayaan repertoar tari selain tari Kuda Lumping sekaligus sebagai tari yang siap dikolaborasikan dengan tari lainya. Kegelisahan yang tengah melanda para seniman desa Gandu akibat kehadiran seni daerah lain dan maraknya kolaborasi yang kurang tepat, diharapkan dapat teratasi dengan kehadiran tari garapan sendiri.

Inovasi kesenian rakyat perlu digalakkan karena banyak kesenian di lingkungan masyarakat pendukungnya semakin terhimpit oleh kemajuan jaman. Apabila tidak diadakan penyegaran maka kemungkinan kesenian tersebut akan mengalami kefakuman dan akhirnya ditinggalkan penontonya. Upaya ini diharapkan dapat membantu ketahanan kesenian rakyat dan semakin digemari penontonya.

Inovasi bentuk pertunjukan merupakan cara untuk menata kembali kesenian Kuda Lumping kelompok Sri Budaya , meliputi penggarapan Konsep sajian memasukkan alur cerita dalam pertunjukan. Membenahi gerak tari Kuda Lumping agar lebih dinamis dan tidak membosankan. Penambahan repertoar tari pada pentunjukan kesenian Kuda Lumping. Selain gerak tari yang digarap, dari segi iringan juga mengalami pembaharuan/inovasi baru. Musik tari Kuda Lumping yang sudah ada diperbaiki lagi dengan menambahkan beberapa musik-musik baru. Penggarapan musiknya lebih ditekankan pada bagian awal (prolog) dan bagian akhir dari sajian tari Kuda Lumping.

Proses pelatihan dilaksanakan selama satu bulan lebih. Masyarakat desa Gandu mayoritas bekerja sebagai petani tembakau, apabila sedang panen tembanaku maka kegiatan disesuaikan dengan kesibukan masyarakat. Selain mengadakan sentuhan pada gerak tari Kuda Lumping, kegiatan inovasi juga membuat karya tari baru yang ditarikan oleh anak-anak dengan judul Geculan. Tari bentuk geculan ini dilakukan oleh sepuluh penari yang nantinya akan dikolaborasi dengan tari Kuda Lumping. Gerak dalam tari Geculan di inspirasi dari gerakan anak-anak yang sedang bermain dan bergurau. Tari yang berdurasi 10 menit 
ini menggunakan topeng dengan karakter lucu untuk mengekspresikan tingkah laku anak-anak yang lucu. Musik yang digunakan untuk mengiringi tari ini mengambil dari gending Gundul-Gundul Pacul yang dikembangkan. Pola-pola musik yang digunakan juga dibuat sederhana dikarenakan para penarinya adalah anak-anak, tujuanya supaya anakanak mudah memahami dan menghafalkan musiknya. Properti yang digunakan untuk tari ini adalah topeng. Dalam hal ini pembuatan properti topeng melalui beberapa tahap yaitu, tahap modeling atau pembuatan master topeng dengan bahan dari tunas pisang yang diukir, Lalu menempelkan beberapa potongan-potongan kertas pada permukaan master topeng hingga membentuk sebuah topeng.

\section{PELATIHAN TARI}

Pelatihan diawali dengan melakukan observasi terhadap gerak tari Kuda Lumping yaitu melihat gerak tari Kuda Lumping dari awal hingga akhir, untuk menentukan garapan "baru" dalam bentuk pertunjukan. Sebelum mengadakan kolaborasi akan dilakukan pembenahan bentuk gerak tari Kuda Lumping, agar lebih tertata dan terlihat bergas. Pembenahan dilakukan untuk koreksi bentuk junjungan kaki yang kurang sesuai, bentuk gerak tangan yang masih kurang kuat (maksimal), gerak lompat-lompat yang kurang tinggi. Semua dilakukan supaya gerak tari Kuda Lumping lebih energik. Mulai gerak awal (sembahan), gerak tengah (kiprahan) sampai gerak akhir dilakukan pembenahan. Sedikit demi sedit dan cenderung diulang gerakan itu diterapkan kepada penari sampai mereka menguasai. Pada dasarnya pembenahan ini tidak mengubah bentuk gerak tari Kuda Lumping asli, supaya tidak mengurangi rasa tradisionalnya yang sudah masuk dalam jiwa para penari. Kami hanya memberikan tawaran sebagai alternatif sebuah bentuk sajian kesenian supaya tidak membosankan, baik pelakunya maupun yang menonton. Harapannya setelah mendapatkan sedikit hal yang berbeda ini akan membangkit geliat berkesenian dan tidak terpengaruh oleh kolaborasi dengan kesenian dari luar daerah. Kesenian lokal akan berkolaborasi dengan bentuk-bentuk kesenian yang berasal dari dalam daerah.

Pelatihan tari Kuda Lumping telah selesai diteruskan dengan membuat tari garapan baru bertema Gecul (lucu) yang ditarikan oleh anak-anak usia sekolah dasar kelas 2-kelas 5. Tari ini menceritakan tentang tigkah laku anak-anak yang sedang bermain bersama-sama. Eksplorasi gerak dilakukan untuk mencari gerak yang tepat untuk anakanak. Pelatihan diawali dengan mengumpulkan anak-anak untuk dilatih gerak dasar tari. Letak desa Gandu di kaki bukit gunung Sumbing sehingga tidak ada sanggar tari untuk berlatih sehingga Anakanak ini belum mempunyai dasar menari, jadi kami melatih mulai awal. Pengenalan gerak tari dimulai dari menirukan gerak seharihari yang biasa mereka lakukan. Gerak dipilih yang lucu untuk mewadahi tema tarian yang akan digarap. Anak-anak agak canggung untuk melakukan gerak tari, karena mereka tidak terbiasa menari, tetapi lama kelamaan mereka juga senang dan terbiasa. Penguasaan gerak tari untuk anak-anak dapat dikatakan cepat menerima dan menghafal. Gerak yang dipilih adalah gerak geleng-geleng yang selalu diulang. Pengulangan gerak banyak dilakukan 
untuk memberi kesan sederhana sesuai dengan konsep tari rakyat. Pemberian gerak disertai dengan ungkapan ekspresi supaya garapan tari kelihatan lebih hidup. Penerapan rasa gerak pada anak memang sedikit sulit dilakukan, karena anak-anak sering bersikap tidak serius untuk mendalaminya. Dengan proses delapan kali latihan maka semua materi dapat dikuasai anak-anak dengan baik. Setelah penggarapan gerak selesai dilanjutkan pengaturan pola lantai yang disesuaikan dengan geraknya, yaitu geculan.

\section{PELATIHAN MUSIK TARI}

Pelatihan musik diawali dengan cara melihat sajian tari Kuda Lumping yang sudah ada. Kemudian, dari melihat sajian tersebut kami mengetahui kekurangan atau ketidak sesuaian iringan dengan gerak tari Kuda Lumping. Dengan begitu, peserta kami berani memperbaiki iringan tari Kuda Lumping serta memberikan inovasi, diantaranya; musik atau gending pembukaan, iringan untuk budhalan, perang, dan gending penutupan. Menyempurnakan iringan yang lama menjadi sebuah iringan baru dengan cara menggabungkan iringan yang lama dengan komposisi baru sehingga menghasilkan iringan inovasi dengan teknik yang baik. Penggarapan musik tari tidak dilakukan secara kesluruhan, tetapi hanya dipilih bagian yang dapat di selaraskan. Musik awal atau introduksi dibuat meriah sebagai iringan tari bagian budalan, agar tidak menjenuhkan. Pencarian nada iringan disela-sela gerak tari betul-betul kami perhatikan untuk menghasikan sebuah iringan tari yang sesuai.

Musik Kuda Lumping pada awalnya sudah ada tinggal mengadakan pembenahan. Berbeda dengan musik tari Geculan, memang harus dibuat iringan baru karena tari ini merupakan bentuk garapan baru. Tahap awal adalah mencari refrensi lagu yang sesuai dengan tari Geculan, kemudian dipilih yang sesuai, yaitu lagu gundul-gundul pacul, dan mengaransemen lagu tersebut. Musik iringan Gundul-gundul pacul, diberi awalan/introduksi untuk masuk kedalam musik tarinya. Penyelarasan iringan dengan garapan tari dilakukan sejak awal supaya anak-anak tidak binggung dalam melakukannya.

\section{PENUTUP}

Desa Gandu Kecamatan Tembarak Kabupaten Temanggung merupakan salah satu desa yang memiliki potensi kesenian yang cukup baik. Hal ini dapat dilihat dari masyarakat desa Gandu yang sangat antusias dalam berkesenian. Hal ini nampak ketika kami menawarkan program inovasi kesenian Kuda Lumping. Melalui beberapa metode yang dilakukan, ternyata masyarakat mampu melaksanakan program kerja dengan lancar. Akan tetapi, dalam sebuah pencapaiannya pasti tidak luput dari berbagai hambatan. Salah satu hambatan yang dapat terlihat jelas yaitu kesibukan warga setempat karena musim panen tembakau.

Dari beberapa hambatan yang ada ternyata mampu diselesaikan dengan berbagai solusi yang ditawarkan dan dapat memecahkan masalah dengan cara berdiskusi antar peserta dan juga masyarakat desa Gandu khususnya kelompok kesenian dan karang taruna desa Gandu. Hasil yang dicapai yaitu hadirnya kesenian Gandu dengan warna yang baru sesuai dengan Inovasi yang dilakukan. 


\section{DAFTAR PUSTAKA}

Hans - Dieter Evers.

1998. Teori Masyarakat: Proses Peradaban

Dalam Sistem Dunia Modern. Jakarta: Yayasan obor Indonesia

Jalaludin Rakhmat.

2002. Psikologi Komunikasi. Bandung: Remaja Rosda karya

Piequesed.

1991. Pertunjukan Rakyat Jawa. Trans. K. R. T. Muhammad Husodo
Pringgokusumo. Yogyakarta: Gadjah Mada University Press.

Soerjono Soekanto.

1982. Teori Sosiologi Tentang Pribadi dalam Masyarakat. Jakarta: Balai Aksara.

Umar Kayam. 1981. Seni Tradisi Masyarakat. Jakarta: Sinar Harapan.

\section{Internet:}

http://kabare.id/welcome/article 